Article

\title{
Modified Carbon Fiber Paper-Based Electrodes Wrapped by Conducting Polymers with Enhanced Electrochemical Performance for Supercapacitors
}

\author{
Sicong Tan, Jiajia Li, Lijie Zhou, Peng Chen, Jiangtao Shi@ and Zhaoyang $\mathrm{Xu}$ * \\ College of Materials Science and Engineering, Nanjing Forestry University, Nanjing 210037, China; \\ 17768109951@163.com (S.T.); jiajiaLinjfu@163.com (J.L.); zhoulijie6688@163.com (L.Z.); \\ 15605170735@163.com (P.C.); shijt@njfu.edu.cn (J.S.) \\ * Correspondence: hughxzy@163.com; Tel./Fax: +86-25-8542-7517
}

Received: 2 September 2018; Accepted: 25 September 2018; Published: 27 September 2018

check for updates

\begin{abstract}
An easy approach to fabricating carbon fiber paper (CFP) based electrodes has been developed. This method can be mainly divided into two steps, for which the mixture of cellulose nanofibers (CNFs) and carbon nanotubes (CNTs) was first deposited on the surface of carbon fiber paper through a vacuum filtration device followed by immersing the hybrid paper into concentrated aniline solution to polymerize polyaniline (PANI). Compared to carbon fiber paper, the acid-treated carbon fiber paper (A-CFP)-based electrode provides more active sites, which are beneficial for the polymerization of polyaniline. The mixture of CNFs and CNTs could coat on the A-CFP by vacuum-filtration due to the high hydrophilicity of A-CFP improved by acid-treatment. PANI with different polymerization time was in-situ synthesized on the surface of the hybrid paper to form a three-dimensional cross-linked structure that greatly enhanced the electrochemical performance of the electrode by improving high capacitance, high rate-capability, and long cycle-life. Moreover, the assembled symmetrical supercapacitor showed a high area capacitance of $626 \mathrm{mF} \cdot \mathrm{cm}^{-2}$ and an energy density of $87 \mu \mathrm{Wh} \cdot \mathrm{cm}^{-2}$. This facile, easy performed, and low-cost strategy may provide a feasible method for the production of supercapacitor electrodes.
\end{abstract}

Keywords: carbon fiber paper; cellulose; carbon nanotubes; polyaniline; supercapacitor

\section{Introduction}

To overcome the severe issue of the rapid consumption of oil resources and global warming problems, much effort has been paid to the development of energy storage devices. Supercapacitors, as an important class of energy-storing devices, have attracted great interest in recent years due to their numerous superior properties such as large capacitance, high power-density, fast charging/discharging rate, and long cycle-life [1-4]. Chiefly, supercapacitors can be divided into two types: Electrical double layer capacitors (EDLC) store energy through fast ion adsorption, while pseudocapacitors work via reversible surface Faradic reactions [5]. Compared with EDLC, pseudocapacitors generally possess higher capacitance and power density considering their electrochemical nature and thus catch more attention [6].

Mainly, pseudocapacitor materials can be categorized into two types: (i) conducting polymers and (ii) transition metal oxides. Through transition metal oxides, $\mathrm{RuO}_{2}, \mathrm{MnO}_{2}$, and $\mathrm{Co}_{3} \mathrm{O}_{4}$ have attracted most attention due to their high theoretical capacitance, and much pioneer work has been done. For instance, Manjusha V. Shelke and his co-workers have successfully synthesized the $\mathrm{RuO}_{2} / \mathrm{CNO}$ nanocomposite using a sol-gel method, and a high capacitance of $570 \mathrm{~F} \cdot \mathrm{g}^{-1}$ for the composite electrode has been achieved in $0.5 \mathrm{M} \mathrm{H}_{2} \mathrm{SO}_{4}$ aqueous solution [7]. Fabrication of $\mathrm{RGO} / \mathrm{MnO}_{2}$ paper has 
also been made using a free template and simple synthesis process, and a high area capacitance of $897 \mathrm{mF} \cdot \mathrm{cm}^{-2}$ has been acquired by Pooi See Lee and his group [8]. For supercapacitors electrodes made by mesoporous $\mathrm{Co}_{3} \mathrm{O}_{4}$ nanosheet decorated with hydrous $\mathrm{RuO}_{2}$ nanoparticle, an enhanced rate performance of $78 \%$ is achieved at current density ranging from 1 to $40 \mathrm{~A} \cdot \mathrm{g}^{-1}$ [9]. However, transition metal oxides suffer from poor power density and cycling [10].

Considering conducting polymers, polyaniline has stood out due to its unique properties including high conductivity, high capacitance, easy synthesis, low cost, and environmental friendliness [11]. Nevertheless, carbon nanotubes are often used as enhancers to improve the electrochemical performance of PANI due the low stability of PANI during charging/discharging process [12]. For example, Wang has designed supercapacitor electrodes based on PANI and carbon black composites through a one-step potentialdynamic co-deposition process, and a high capacitance of $458 \mathrm{~F} \cdot \mathrm{g}^{-1}$ has been achieved at $2 \mathrm{mV} \cdot \mathrm{s}^{-1}$ [13]. Compared to carbon black, CNTs have been used extensively to improve the electrochemical performance of PANI due to its high conductivity, high aspect ratio, high mechanical strength, and chemical stability $[14,15]$. Significant efforts have been devoted to the fabrication of CNTs/PANI electrodes $[16,17]$. Moreover, CNTs have been demonstrated to show superior properties when used as electrode materials, since they lower the resistance and increase the energy efficiency of electrodes [18].

Both PANI and CNTs suffer from low hydrophobicity, which is not beneficial for contact between electrodes and electrolytes $[19,20]$. Cellulose, as the most abundant and sustainable biopolymer on earth, has attracted much attention due to its several remarkable properties such as high aspect ratio, good mechanical properties, low cost, and superior hydrophilics, and has been applied to many fields including the textile industry, the biomedical field, and typically, wearable and flexible electronic devices [21-25]. The mesoporous structure of CNFs can provide diffusion channels for electrolytes, and its excellent hydrophilic property may help improve the hydrophobicity of CNTs and PANI.

In this work, we report a simple and low-cost "vacuum-filtering and in situ growth" method to fabricate carbon fiber paper based electrodes. CFP was first activated by $\mathrm{H}_{2} \mathrm{SO}_{4} / \mathrm{HNO}_{3}$ mixed acid to improve its poor hydrophobicity and low surface area. Then, an extremely thin layer of CNFs/CNTs hybrid mixture was deposited on the surface of CFP, and the hybrid electrode was later immersed into concentrated aniline solution. After several hours of polymerization, the supercapacitor electrodes could be achieved. The thin layer of CNFs/CNTs mixture not only provides diffusion channels for the electrolyte ions but also offers extra conducting channels that may enhance the electrochemical performance of the electrode. The resulting A-CFP/CNFs-CNTs/PANI electrode exhibits huge area capacitance and excellent cycle ability. FT-IR spectroscopy, X-ray diffraction, XPS, Raman, and BET measurement were used to characterize chemical properties of the A-CFP/CNFs-CNTs/PANI electrode, while cyclic voltammetry (CV), galvanostatic charge-discharge (G-CD), and electrochemical impedance spectroscopy (EIS) were used to evaluate its electrochemical quality.

\section{Experimental}

\subsection{Materials}

The raw CFP for the preparation of functionalized carbon fiber paper (thickness $0.02 \mathrm{~mm}$, density $0.78 \mathrm{~g} \cdot \mathrm{cm}^{-3}$, resistivity $2.5 \mathrm{~m} \Omega \cdot \mathrm{cm}^{-2}$ ) was bought from Shanghai Hesen Electric. Co. Ltd., Shanghai, China. Raw bamboo powder provided by Hangzhou gaoke composite co. LTD, Zhejiang, China was obtained for the production of cellulose nanofibers. Multiwalled carbon nanotubes were achieved from Shenzhen Nanotech Port Co., Ltd., Shenzhen, China. Pure aniline monomers and ammonium persulfate were obtained from Shanghai Ling Feng Chemical Reagent Co., Ltd., Shanghai, China. All the reagents were in analytical grade and used without purification. 


\subsection{Preparation of Activated Carbon Fiber Paper}

The activation process of CFP was performed according to the literature [26]. Just in brief, the raw CFP was cut into small pieces with a geometric area of $4.5 \times 4.5 \mathrm{~cm}^{2}$. After washed several times with deionized water and ethanol, the CFP was dried at $60^{\circ} \mathrm{C}$ for $12 \mathrm{~h}$. The pre-treated CFP was then immersed into a mixed acid containing both sulfuric acid and nitric acid (volume ration $3: 1$ ) at $60^{\circ} \mathrm{C}$ for $1 \mathrm{~h}$. The acid-treated CFP was denoted as A-CFP.

\subsection{Preparation of Cellulose Nanofibers}

The synthesis process was performed according to the literature and adapted with small modifications [27]. Just in brief, $10 \mathrm{~g}$ of bamboo powder was added into $500 \mathrm{~mL}$ water containing $10 \mathrm{~g} \mathrm{KOH}(98 \%)$ and intensively stirred at $75{ }^{\circ} \mathrm{C}$ for $1 \mathrm{~h}$ for five times to remove lignin from bamboo powder. Then, a certain amount of potassium hydroxide was added into the solution and mechanical stirred at $90^{\circ} \mathrm{C}$ for $2 \mathrm{~h}$ to remove hemi-cellulose and other impurities. Further, the sample was treated with acidified sodium chlorite $(5 \mathrm{~g}, 98 \%)$ solution at $75^{\circ} \mathrm{C}$ for $1 \mathrm{~h}$ and potassium hydroxide at $90^{\circ} \mathrm{C}$ for $2 \mathrm{~h}$ to improve its purity. Lastly, $12 \mathrm{~mL}$ hydrochloric acid $(2 \mathrm{~mL}, 98 \%)$ was added into the solution and kept stirring at $80^{\circ} \mathrm{C}$ for $2 \mathrm{~h}$. After chemical treatment, the samples were mechanically polished to get a CNFs slurry. Deionized water was used to remove excess reagent at every step to keep $\mathrm{pH}$ of the sample neutral.

\subsection{Preparation of A-CFP Based Electrodes}

The experimental process is shown in Figure 1. All the chemicals were of analytical grade and used without further purification. In a typical process, $10 \mathrm{mg}$ CNFs and $10 \mathrm{mg}$ CNTs (mass ration $=1: 1$ ) were added into $100 \mathrm{~mL}$ deionized water followed by adding $40 \mathrm{mg}$ sodium dodecyl benzene sulfonate (SDBS) as dispersant. The mixed solution was ultrasounded for $30 \mathrm{~min}$ to achieve a homogeneous solution and was then coated on the surface of A-CFP through a vacuum filtration device. CNFs/CNTs deposited on A-CFP with different weight was denoted as $\mathrm{CCM}_{\mathrm{p}-5}, \mathrm{CCM}_{\mathrm{p}-10}$, and $\mathrm{CCM}_{\mathrm{p}-15}$, respectively. Then, $5 \mathrm{mmol}$ aniline monomers were dissolved in $100 \mathrm{~mL} 1 \mathrm{M} \mathrm{HCl}$ and magnetically stirred for several seconds. A piece of $\mathrm{CCM}_{\mathrm{p}-10}$ was immersed into the solution as mentioned above to adsorb aniline monomers for an hour followed by adding $5 \mathrm{mmol}$ ammonium persulfate for the polymerization of PANI. The polymerization was carried out for 2, 4, 6, 8, and $24 \mathrm{~h}$, and the obtained samples were denoted as $\mathrm{CCM}_{\mathrm{s}-2}, \mathrm{CCM}_{\mathrm{s}-4}, \mathrm{CCM}_{\mathrm{s}-6}, \mathrm{CCM}_{\mathrm{s}-8}$, and $\mathrm{CCM}_{\mathrm{s}-24}$ respectively. The whole hybrid paper of $\mathrm{CCM}_{\mathrm{s}-2}, \mathrm{CCM}_{\mathrm{s}-4}, \mathrm{CCM}_{\mathrm{s}-6}, \mathrm{CCM}_{\mathrm{s}-8}$, and $\mathrm{CCM}_{\mathrm{s}-24}$ weighted about $14.5,15.6,16.5,18$, and $21.2 \mathrm{mg} \cdot \mathrm{cm}^{-2}$ (for $\mathrm{CCM}_{\mathrm{s}-\mathrm{x}}, \mathrm{x}$ means the polymerization time of PANI). PANI was also polymerized directly on the surface of A-CFP without CNFs/CNTs for the purpose of comparison and was denoted as $\mathrm{C}_{\mathrm{p}-6}$.

\subsection{Assemble of the Symmetric Supercapacitors (ASSC)}

$5 \mathrm{~mL} \mathrm{H}_{2} \mathrm{SO}_{4}$ and $5 \mathrm{~g}$ polyvinyl alcohol was added into $10 \mathrm{~mL}$ deionized water and mechanically stirred for $2 \mathrm{~h}$ at $85{ }^{\circ} \mathrm{C}$ to achieve clear gel electrolyte. The CFP based electrodes were cut into rectangular shapes $\left(2 \times 1 \mathrm{~cm}^{2}\right)$ and then immersed into gel for $30 \mathrm{~min}$. The two electrodes were air dried at room temperature for about $4 \mathrm{~h}$ to evaporate the excess water and compressed together at $0.2 \mathrm{MPa}$ for $10 \mathrm{~min}$ to form the symmetric supercapacitor.

\subsection{Chemical Characterization and Electrochemical Measurements}

Functional groups of synthesized electrodes were detected using a FTIR spectrometer with an attenuated total reflectance (ATR) device in the wave number range from 4000 to $500 \mathrm{~cm}^{-1}$ (Nicolet iS10, Thermo Electron Corp., Waltham, MA, USA). XRD patterns of the samples were conducted using an X-ray diffractometer with $\mathrm{Cu}$ Ka radiation $(40 \mathrm{kV}$ and $30 \mathrm{~mA})$ at a scanning rate of $5^{\circ} / \mathrm{min}$ (Ultima IV, Rigaku, Tokyo, Japan). Photoelectron spectroscopy (XPS) and Raman spectroscopy 
analyses were also performed to understand the surface distribution of functional groups and the molecular structure. A field emission scanning electron microscopy (FE-SEM, S-4800, HITACHI, Tokyo, Japan) was conducted at $5.0 \mathrm{kV}$ to characterize the morphology and structure of the samples. Brunauer-Emmett-Teller (BET) measurement was conducted using an ASAP 2020 V3.00 H surface area analyzer to determine the $\mathrm{N}_{2}$ adsorption/desorption.

The electrochemical performances of the samples were characterized using a three-electrode system. Mainly, $\mathrm{CCM}_{\mathrm{s}-\mathrm{x}}$ were cut into $2 \times 1 \mathrm{~cm}^{2}$ and used directly as working electrodes without any conductive binders. Aqueous solution of $1 \mathrm{M} \mathrm{H}_{2} \mathrm{SO}_{4}$ was used as electrolyte. Cyclic voltammetry (CV), galvanostatic charge-discharge (GCD), and EIS were tested using a CHI660E electrochemical workstation (from Chenhua, Shanghai, China) to determine the electrochemical performances of the samples. The electrochemical performances of the ASSC was tested in a two-electrode system using $\mathrm{Na}_{2} \mathrm{SO}_{4}$ as electrolyte.

The specific capacitance, energy densities, and power densities of the samples were calculated using the following equations:

$$
\begin{gathered}
C_{A}=Q / A \times \Delta V=\frac{\int I d V}{v s \Delta V} \\
C_{A}=Q / A \times \Delta V=\frac{I \Delta t}{S \Delta V} \\
E=\frac{1}{2} C_{A}(\Delta V)^{2} \\
P=\frac{E}{\Delta t}
\end{gathered}
$$

in which $C_{A}$ represents the specific area capacitance of the electrodes, $P$ represents power density, $E$ means energy density, $\int I d V$ means the integral area of $C V$ curves calculated by origin software, $s$ is the geometric area of the electrodes, $v$ is the potential sweep rate, and $\Delta V$ is a total potential deviation of the voltage window (including IR drop). $I$ is the constant discharge current, while $\Delta t$ means the discharge time.

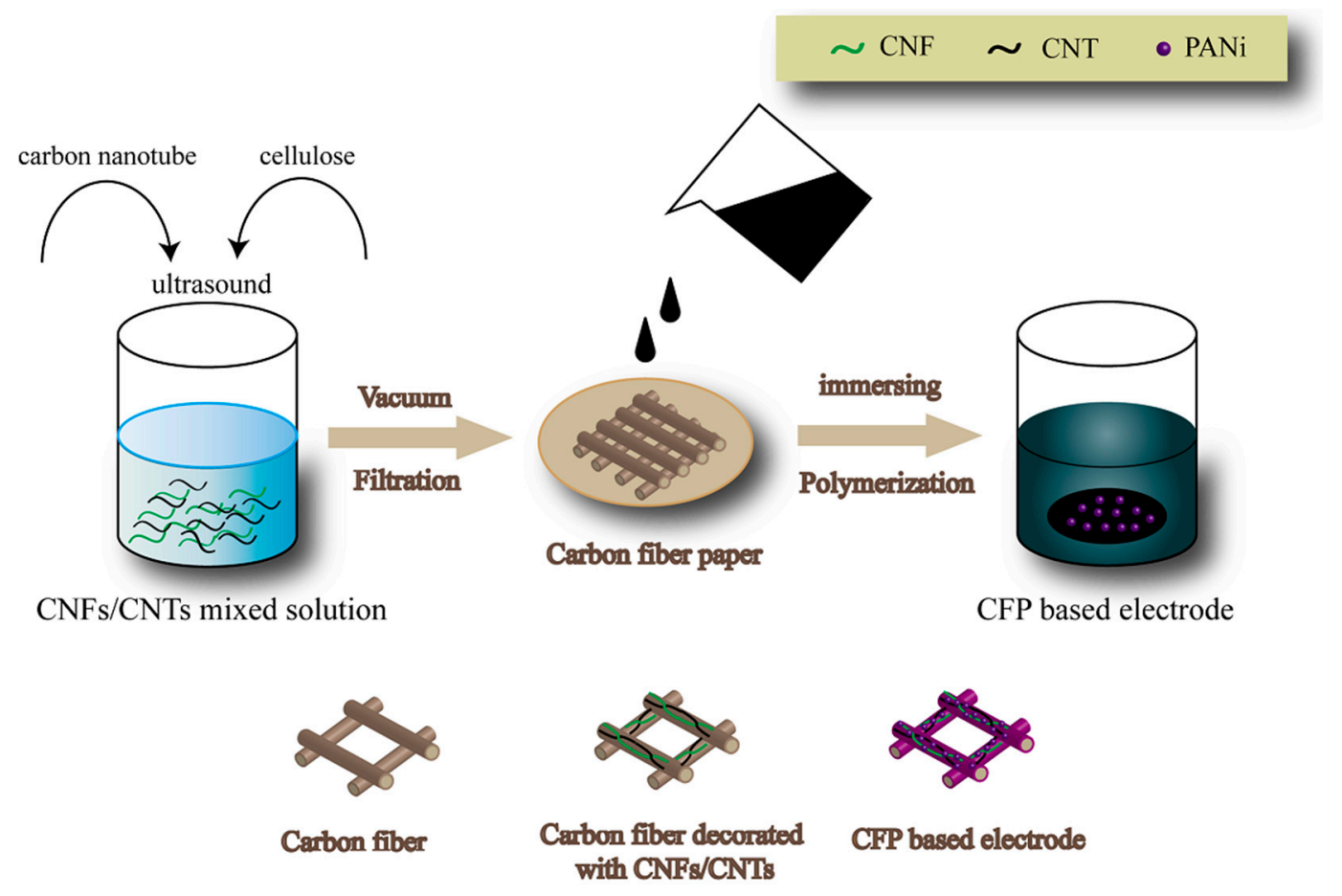

Figure 1. Experimental process of the samples. 


\section{Results and Discussion}

\subsection{SEM Images}

The morphology of the CFP (Figure 2a,b), A-CFP (Figure 2d,e), and CCM $\mathrm{P}_{\mathrm{p}-10}$ (Figure 2c,f) are shown in Figure 2 with different magnifications. The diameter of carbon fibers of both CFP and A-CFP are 7 micrometers approximately and much polytetrafluoroethylene (PTFE) can be observed filling in the vacancy among the carbon fibers, which is a necessary binder material for the production of CFP. Oxygen-containing groups were functionalized on the surface of the CFP due to the following reaction (5):

$$
\mathrm{CFP}+\mathrm{H}_{2} \mathrm{SO}_{4} / \mathrm{HNO}_{3} \rightarrow \mathrm{CFP}-\mathrm{OH} / \mathrm{CFP}-\mathrm{COOH}
$$

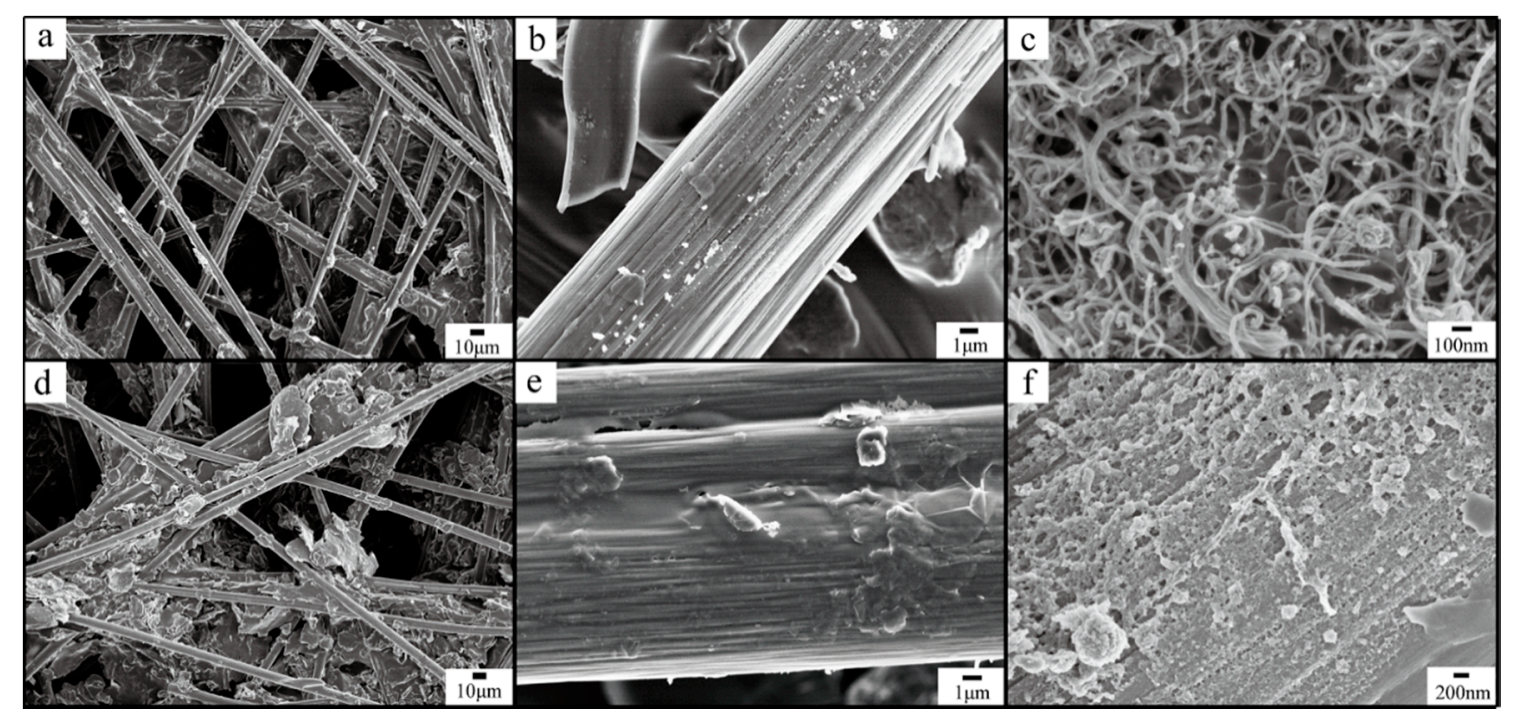

Figure 2. SEM images of low magnification of raw carbon fiber papers (a), high magnification of raw carbon fiber papers (b), CNFs/CNTs mixture deposited on the surface of A-CFP $\left(\mathrm{CCM}_{\mathrm{p}-10}\right)(\mathbf{c})$, low magnification of activated carbon fiber papers (d), high magnification of activated carbon fiber papers (e), and the opposite side of $\mathrm{CCM}_{\mathrm{p}-10}(\mathbf{f})$.

Further, the morphology of A-CFP shown in Figure $2 \mathrm{~d}$ remained unchanged but became rougher, which can be seen in Figure 2e. For $\mathrm{CCM}_{\mathrm{p}-10}$ (Figure 2c), both CNFs and CNTs with a diameter range between 10 and $50 \mathrm{~nm}$ can be identified fully covered on the surface of A-CFP. Moreover, the 3D porous network structure composed by crossed entangled CNFs and CNTs provided more active sites for the adsorption of PANI. Figure $2 \mathrm{f}$ confirmed the attachment of CNFs on the surface of a single carbon fiber, which demonstrated that the mixture of CNFs/CNTs penetrated into the deep inner space of carbon fiber paper. Differed from A-CFP, the deposited CNFs/CNTs mixture with porous 3D network provided large surface area $\left(97.8 \mathrm{~m}^{2} \cdot \mathrm{g}^{-1}\right)$ for the polymerization of PANI. Moreover, the good hydrophilicity of CNFs may improve the contact between active materials and electrolytes and reduce the diffusion distance of electrolyte ions during the charge/discharge process.

Morphology of PANI directly coated on A-CFP is shown in Figure 3a. PANI with a diameter of approximately $600 \mathrm{~nm}$ was partially deposited on the surface of A-CFP. The inset of Figure 3a shows the enlarged photograph of $\mathrm{C}_{\mathrm{p}-6}$. Morphology of PANI with different polymerization times deposited on the surface of $\mathrm{CCM}_{\mathrm{p}-10}$ are shown in Figure 3b-f. As shown in Figure 3b, PANI layers were first coated onto the surface of CNFs and CNTs to form a core-shell nanostructure via in situ polymerization. The diameter of PANI coated on the CNFs and CNTs ranged between 100 and $200 \mathrm{~nm}$. The construction of this interconnected three-dimensional conducting network made electrons transfer not only via junctions of CNTs but also through PANI and thus a minimized junction contact resistance could be achieved. Furthermore, this unique structure could act as a buffering layer to prevent the 
severe agglomeration of PANI, and the matrix of CNFs/CNTs could reduce the swelling and shrinking of PANI during the charging/discharging process. In Figure $3 c$, the structure of $\mathrm{CCM}_{\mathrm{s}-4}$ became more compact and porous, which indicated the higher conversion degree of aniline monomer to PANI. For $\mathrm{CCM}_{\mathrm{s}-6}$, the PANI layer became denser and less porous, which can be observed from Figure $3 \mathrm{~d}$. For longer polymerization time of $8 \mathrm{~h}$, the fiber-like PANI totally disappeared, while large-scale of agglomeration could be seen, which have been due to the strong hydrogen bonding between sequentially formed PANI layers. For $\mathrm{CCM}_{\mathrm{s}-24}$, PANI was densely packed, and an extra criss-cross structure could be observed.

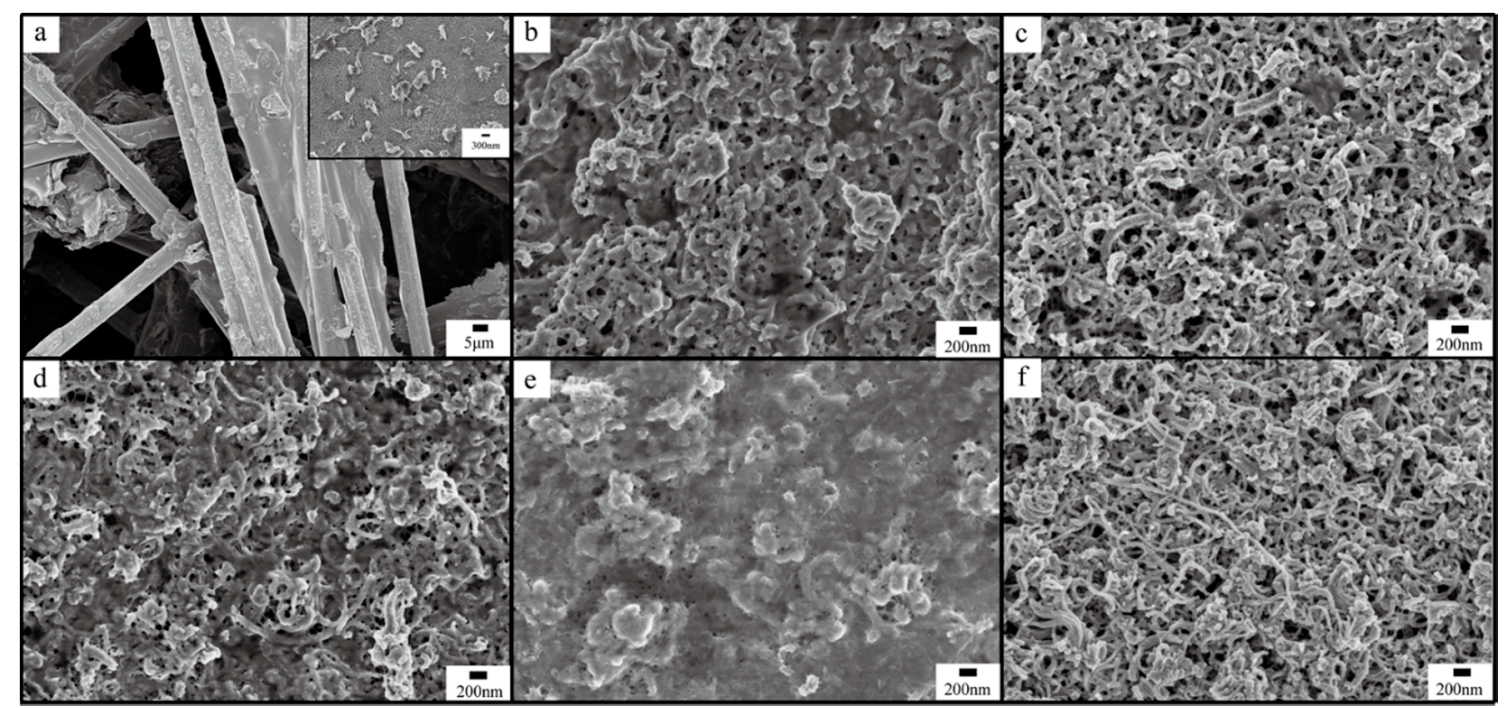

Figure 3. SEM images of PANI directly polymerized on the surface of A-CFP $\left(\mathrm{C}_{\mathrm{p}-6}\right)(\mathbf{a}), \mathrm{CCM}_{\mathrm{s}-2}(\mathbf{b})$, $\mathrm{CCM}_{\mathrm{s}-4}(\mathbf{c}), \mathrm{CCM}_{\mathrm{s}-6}(\mathbf{d}), \mathrm{CCM}_{\mathrm{s}-8}(\mathbf{e})$, and $\mathrm{CCM}_{\mathrm{s}-24}(\mathbf{f})$.

\subsection{FTIR Analysis}

The typical FTIR spectra of CFP is shown in Figure 4a, in which peaks centered at $1057 \mathrm{~cm}^{-1}$ represented the vibrational mode of $\mathrm{C}-\mathrm{O}$ groups. In Figure $4 \mathrm{~b}$, the appearance of strong peak located at $1632 \mathrm{~cm}^{-1}$ was caused by the carbonyl group $(\mathrm{C}=\mathrm{O})$, and the broad peak from 2900 to $3700 \mathrm{~cm}^{-1}$ was attributed to $\mathrm{N}-\mathrm{H}$ bonds, which confirmed the successfully oxidation of raw $\mathrm{CFP}$ with the mixed solution of $\mathrm{H}_{2} \mathrm{SO}_{4}$ and $\mathrm{HNO}_{3}$, and this was further confirmed by XPS [26,28]. Figure 4c exhibited the FTIR spectra of $\mathrm{CCM}_{\mathrm{p}-10}$; the oxidation peak at $1627 \mathrm{~cm}^{-1}$ was obviously weakened, and the peak at $3244 \mathrm{~cm}^{-1}$ disappeared totally; thus, a relatively smooth curve can be observed, which may due to the coverage and symmetric structure of CNTs [29]. Characteristic peaks of PANI centered at 827, 1194,1282 , and $1520 \mathrm{~cm}^{-1}$ can be seen in Figure $4 \mathrm{~d}$, and they were caused by $\mathrm{N}-\mathrm{H}$ vibration of the secondary amine, the bending of $\mathrm{C}-\mathrm{H}$ group, $\mathrm{C}-\mathrm{N}$ stretching of secondary aromatic amines, and the stretching of $\mathrm{N}=\mathrm{Q}=\mathrm{N}$ groups, respectively [30].

\subsection{XRD Analysis}

XRD patterns were used to characterize the possible phase of the products. For CFP and A-CFP, peaks centered at about $26.3^{\circ}$ and $54.5^{\circ}$ can be indexed to a hexagonal graphite (JCPDF \# 41-1487), and no other peaks were detected suggesting good purity of the samples. Compared to CFP, the peak intensity of A-CFP was much lower, which indicated the degradation of high crystalline-structure of graphite [31]. In Figure 5c, typical peaks of CFP were still detected, but the intensity became lower, which may have been due to the coverage of CNFs/CNTs mixture, and the new emerged peak located at about $22.5^{\circ}$, which was attributed to the typical cellulose I structure [32]. However, peaks of CNFs completely disappeared, and peaks of PANI did not show up at all (Figure 5d). With comparison to $\mathrm{CCM}_{\mathrm{p}-10}$, XRD pattern of $\mathrm{CCM}_{\mathrm{s}-6}$ showed typical peaks of CFP and A-CFP with increased intensity, which may have been caused by the different scales among the components. 


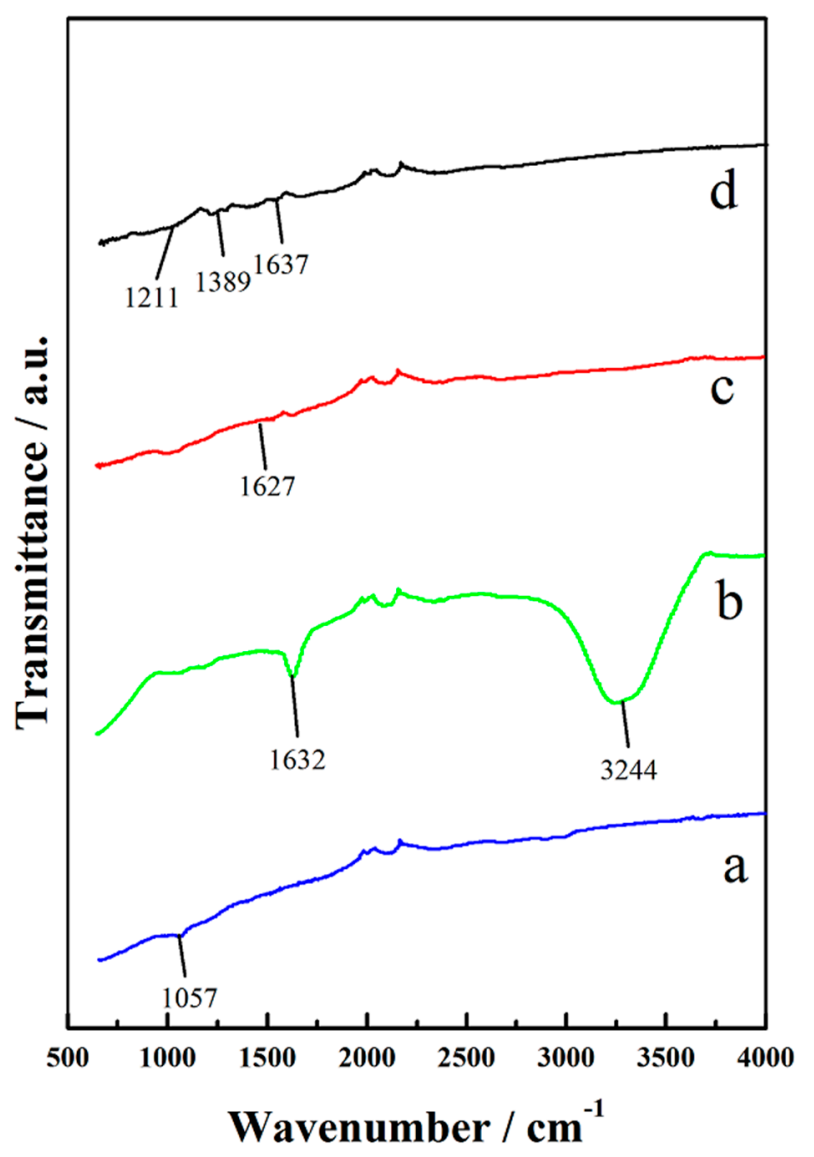

Figure 4. FTIR spectra of the raw CFP (a), A-CFP (b), $\mathrm{CCM}_{\mathrm{p}-10}(\mathbf{c})$, and $\mathrm{CCM}_{\mathrm{s}-6}(\mathbf{d})$.

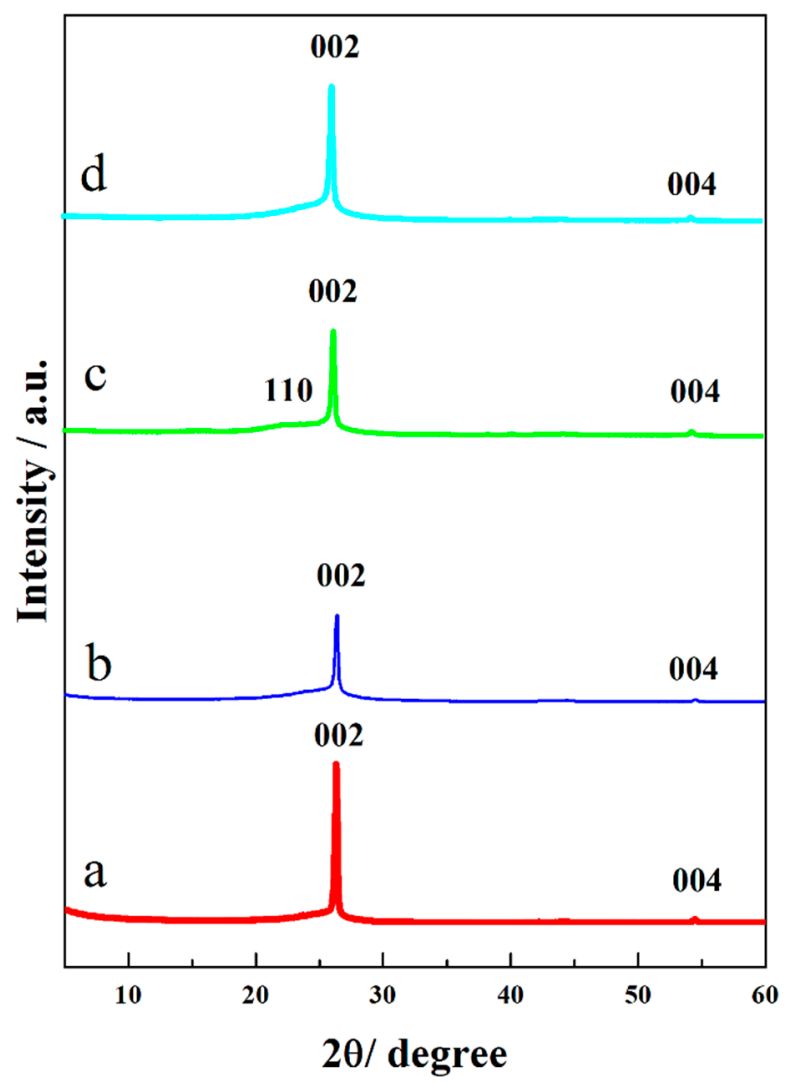

Figure 5. XRD patterns of raw $\mathrm{CFP}(\mathbf{a}), \mathrm{A}-\mathrm{CFP}(\mathbf{b}), \mathrm{CCM}_{\mathrm{p}-10}(\mathbf{c})$, and $\mathrm{CCM}_{\mathrm{s}-6}(\mathbf{d})$. 


\subsection{Raman Analysis}

Raman spectra was captured to further characterize the surface structure of the samples. In Figure 6a, typical peaks centered at 1348, 1585, and $2711 \mathrm{~cm}^{-1}$ corresponded to the $\mathrm{D}, \mathrm{G}$, and 2D bands of carbon materials. Moreover, the D-band was related to the presence of disorder in $\mathrm{sp}^{2}$-hybridized carbon of carbon fibers, while G-band was caused by the hexagonal ring of the graphitic sp ${ }^{2}$ carbon fibers. For A-CFP in Figure $6 \mathrm{~b}$, the ratio of $I_{D} / I_{G}$ and $I_{2 D} / I_{G}$ increased from 0.91 to 1.2 and decreased from 0.25 to 0.05 , respectively, which implied that more defects were introduced into the graphite planes [30]. In Figure 6c, peaks centered at 1338, 1574, and 2673 were all in accordance with Raman spectra of CNTs and were caused by the disorder-induced D-band, the derived graphite tangential G-band, and the second-order harmonic $\mathrm{G}^{\prime}$-band, respectively [33]. Considering Raman spectra of $\mathrm{CCM}_{\mathrm{s}-6}$ in Figure $6 \mathrm{~d}$, all the peaks almost remained at their location in Figure $6 \mathrm{c}$, but the intensity became much higher, which may confirm the good combination among the components.

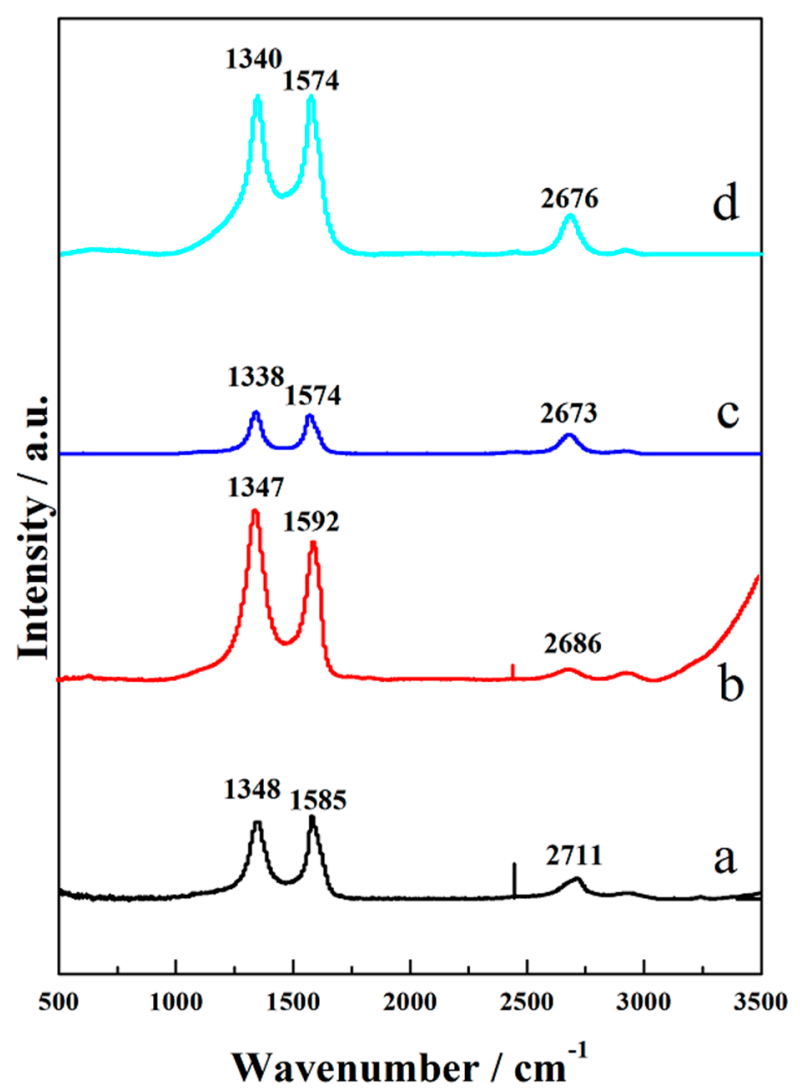

Figure 6. Raman spectra of the raw $\operatorname{CFP}(\mathbf{a}), \mathrm{A}-\mathrm{CFP}(\mathbf{b}), \mathrm{CCM}_{\mathrm{p}-10}(\mathbf{c})$, and $\mathrm{CCM}_{\mathrm{s}-6}(\mathbf{d})$.

\subsection{XPS Analysis}

X-ray photoelectron spectra was used extensively to further characterize the surface functional groups of the samples. Figure 7a showed the wide scan XPS spectra of the raw CFP and A-CFP. Typically, after chemical treatment by mixed $\mathrm{H}_{2} \mathrm{SO}_{4} / \mathrm{HNO}_{3}$, the intensity of $\mathrm{C}$ 1s of the raw CFP decreased, while the intensity of $\mathrm{O} 1 \mathrm{~s}$ increased, which indicated that more oxygen-containing groups were introduced into A-CFP. Moreover, the arising peak of N1s in the A-CFP suggested that $\mathrm{HNO}_{3}$ and $\mathrm{H}_{2} \mathrm{SO}_{4}$ can provide nitrogen and sulfer containing groups on the surface of CFP [34]. XPS spectra of both $\mathrm{CCM}_{\mathrm{p}-10}$ and $\mathrm{CCM}_{\mathrm{s}-6}$ are shown in Figure $7 \mathrm{~b}, \mathrm{c}$. The intensity decrease of O1s in A-CFP may demonstrate that sufficient PANI was deposited on the surface of CNFs/CNTs. For narrow C1s XPS spectrum of $\mathrm{CCM}_{\mathrm{s}-6}$, the binding energy peak centered at $284.5 \mathrm{eV}$ can be mainly attributed to the in-plane $\mathrm{C}-\mathrm{C}$ bending or the $\mathrm{C}-\mathrm{H}$ bonds. The wide peak centered at $286.3 \mathrm{eV}$ can be assigned to the 
C-N bond [35]. Peaks centered at about 287.5 and $289.6 \mathrm{eV}$ derived from the carboxyl and hydroxyl groups bonded with carbon fibers [36].
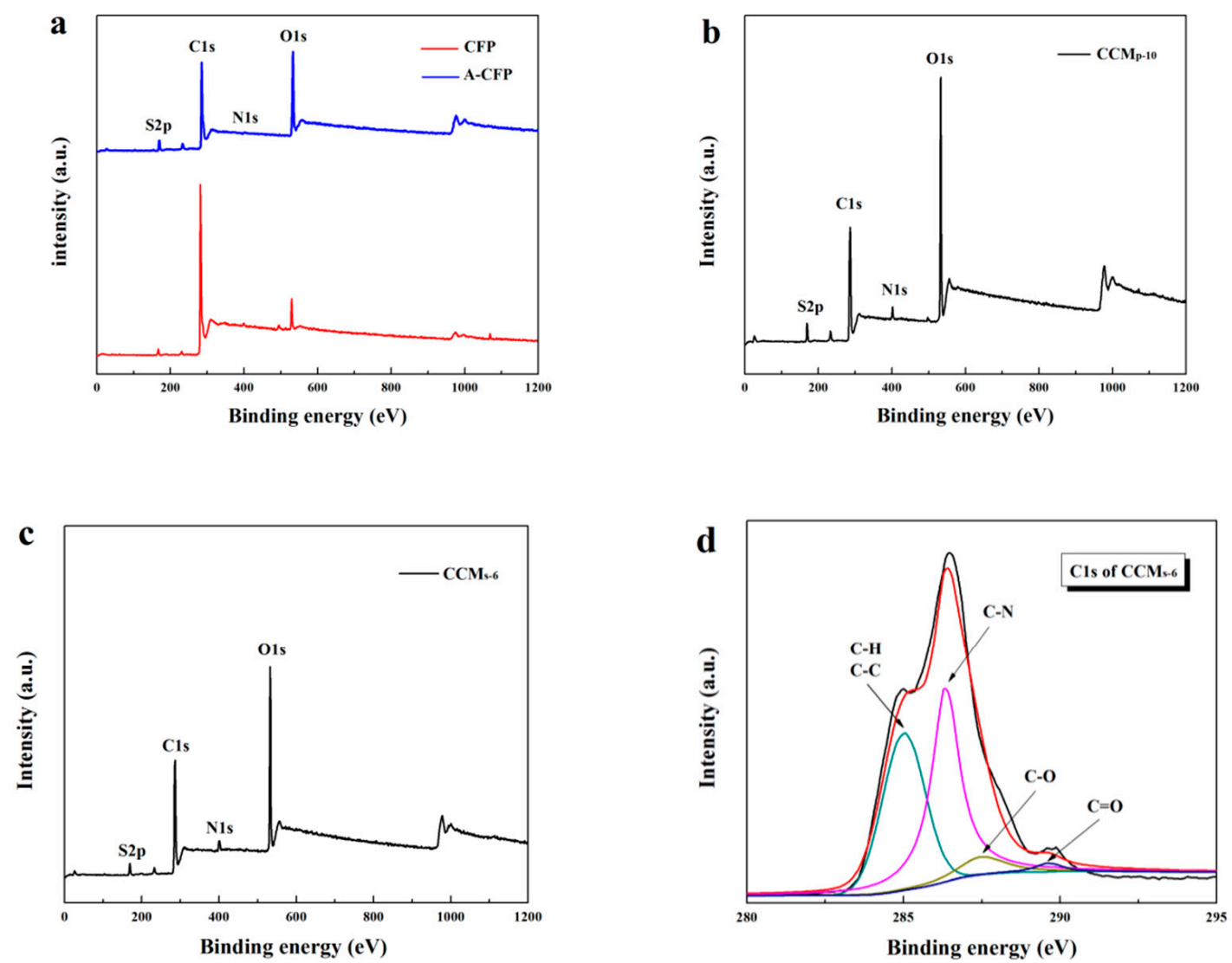

Figure 7. X-ray photoelectron spectra of the raw CFP and A-CFP (a), $\mathrm{CCM}_{\mathrm{p}-10}(\mathbf{b}), \mathrm{CCM}_{\mathrm{s}-6}(\mathbf{c})$, and narrow scan $\mathrm{C} 1$ s of the $\mathrm{CCM}_{\mathrm{s}-6}(\mathbf{d})$.

\subsection{BET Analysis}

A nitrogen gas adsorption/desorption technique was used to test the specific surface area of the obtained samples. As shown in Figure 8, the adsorption isotherm of all the materials were in type IV according to IUPAC. The specific surface area of the activated carbon fiber paper was measured to be $133.3 \mathrm{~m}^{2} \cdot \mathrm{g}^{-1}$, which was approximately 8.5 -fold higher than the raw carbon fiber $\left(15.9 \mathrm{~m}^{2} \cdot \mathrm{g}^{-1}\right)$. This demonstrated that the acid treatment of mixed $\mathrm{H}_{2} \mathrm{SO}_{4}$ and $\mathrm{HNO}_{3}$ indeed increased the surface area of CFP. For $\mathrm{CCM}_{\mathrm{p}-10}$, the surface area decreased little $\left(116.2 \mathrm{~m}^{2} \cdot \mathrm{g}^{-1}\right)$ compared to A-CFP. Although the deposited mixture of CNFs/CNTs did not increase the specific of the material, it provided more active sides for the growth of PANI. This result was consistent with the SEM image and was beneficial for energy-storage devices. 


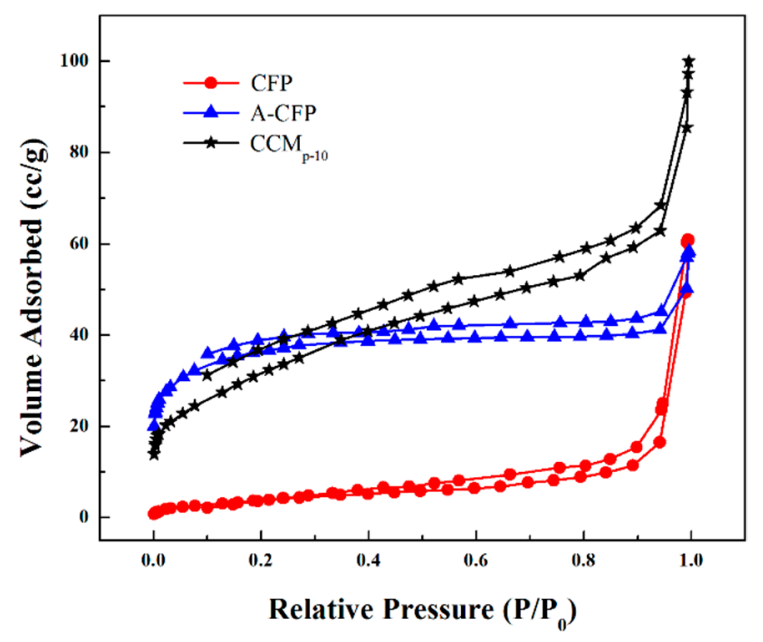

Figure 8. BET Nitrogen adsorption/desorption isotherm of the raw CFP, the A-CFP, and the CCM $\mathrm{P}_{\mathrm{p}}$.

\subsection{Electrochemical Characterization}

Electrochemical performances of the samples were evaluated using an electrochemical workstation (CHI660E) in $1 \mathrm{M} \mathrm{H}_{2} \mathrm{SO}_{4}$ electrolyte, with a Pt electrode as the counter electrode and a saturated calomel electrode (SCE) as the reference electrode. The total mass of CNFs/CNTs mixture deposited on the surface of A-CFP was fixed to be $20 \mathrm{mg}$ (weight ratio 1:1). As depicted in Figure 9a, CV loops of $\mathrm{CCM}_{\mathrm{p}-10}$ at different scan rates all showed a nearly symmetrical rectangle shape, which indicted an ideal capacity property. The capacitance of $\mathrm{CCM}_{\mathrm{p}-10}$ was determined to be approximately 1300,1235 , 1057,927 , and $697 \mathrm{mF} \cdot \mathrm{cm}^{-2}$ at 5, 10, 30, 50, and $100 \mathrm{mV} \cdot \mathrm{s}^{-1}$, respectively. For comparison, CV curves of CFP, A-CFP, $\mathrm{CCM}_{\mathrm{p}-5}, \mathrm{CCM}_{\mathrm{p}-10}$, and $\mathrm{CCM}_{\mathrm{p}-15}$ performed at $100 \mathrm{mV} \cdot \mathrm{s}^{-1}$ are shown in Figure 9c. The pure CFP showed a small capacitance of $2.28 \mathrm{mF} \cdot \mathrm{cm}^{-2}$, while A-CFP possessed a much higher capacitance of $740 \mathrm{mF} \cdot \mathrm{cm}^{-2}$, which was almost 325 times larger than the former. This can be mainly attributed to the increase of surface area that benefits for the EDL capacity. The obvious redox pair derived from PANI appeared in the CV curve and analysis of XPS confirmed that the extra capacitance was provided by pseudocapacitive contribution derived from the oxygen-containing functional groups of A-CFP [33]. The detailed mechanisms are explained by the following reactions (6)-(8) [26]:

$$
\begin{gathered}
\mathrm{CFP}-\mathrm{COOH} \rightleftharpoons \mathrm{CFP}-\mathrm{COO}+\mathrm{H}^{+}+\mathrm{e}^{-} \\
\mathrm{CFP}-\mathrm{OH} \rightleftharpoons \mathrm{CFP}=\mathrm{O}+\mathrm{H}^{+}+\mathrm{e}^{-} \\
\mathrm{CFP}=\mathrm{O}+\mathrm{e}^{-} \rightleftharpoons \mathrm{CFP}_{-} \mathrm{O}^{-}
\end{gathered}
$$

When it comes to $\mathrm{CCM}_{\mathrm{p}-5}, \mathrm{CCM}_{\mathrm{p}-10}$, and $\mathrm{CCM}_{\mathrm{p}-15}$, smaller $\mathrm{CV}$ areas can be observed, which may be due to the insulativity of CNF, but a high capacitance of 507,697 , and $703 \mathrm{mF} \cdot \mathrm{cm}^{-2}$ can still be achieved. GCD tests were further used to characterize the charging/discharging performance of the samples. As it is clearly seen in Figure 9b, all the GCD curves are closely linear, and no obvious voltage drop can be observed that further identifies the good electrochemical performance of $\mathrm{CCM}_{\mathrm{p}-10}$. A high specific-area capacitance of 730,682 , and $630 \mathrm{mF} \cdot \mathrm{cm}^{-2}$ was achieved, respectively, as the discharge currents verified from 1 to $5 \mathrm{~mA} \cdot \mathrm{cm}^{-2}$. These results are comparable with those obtained from $\mathrm{CV}$ loops, and about $86.3 \%$ of the initial capacity was retained when it was charged to $5 \mathrm{~mA} \cdot \mathrm{cm}^{-2}$, which indicated the good rate capability of the free-standing electrode. Comparison of GCD curves of CFP, A-CFP, $\mathrm{CCM}_{\mathrm{p}-5}, \mathrm{CCM}_{\mathrm{p}-10}$, and $\mathrm{CCM}_{\mathrm{p}-15}$ are exhibited in Figure $9 \mathrm{~d}$. A high capacitance of $976 \mathrm{mF} \cdot \mathrm{cm}^{-2}$ at $1 \mathrm{~mA} \cdot \mathrm{cm}^{-2}$ for A-CFP was achieved, which was nearly 1621 times higher than the raw CFP. A relatively similar value of 721,730 , and $707 \mathrm{mF} \cdot \mathrm{cm}^{-2}$ was obtained for $\mathrm{CCM}_{\mathrm{p}-5}, \mathrm{CCM}_{\mathrm{p}-10}$, and $\mathrm{CCM}_{\mathrm{p}-15}$. Although the existence of CNFs/CNTs lowers the capacitance of the A-CFP, which may due to the high resistance of CNFs, but the high hydrophilic property of CNFs may enhance the rate capability 
of A-CFP [37]. Typically, with the increasing of discharge current from 1 to $5 \mathrm{~mA} \cdot \mathrm{cm}^{-2}$, an increased rate capability of $80.0 \%, 86.3 \%$, and $87.0 \%$ was achieved compared to A-CFP (83\%). Considering that further increment of the weight of CNFs/CNTs mixture may lower the capacitance overmuch, we choose $\mathrm{CCM}_{\mathrm{p}-10}$ as the substrate to further polymerize PANI, and the deposited CNFs/CNTs mixture is expected to improve the rate capability and cycling performance of PANI.
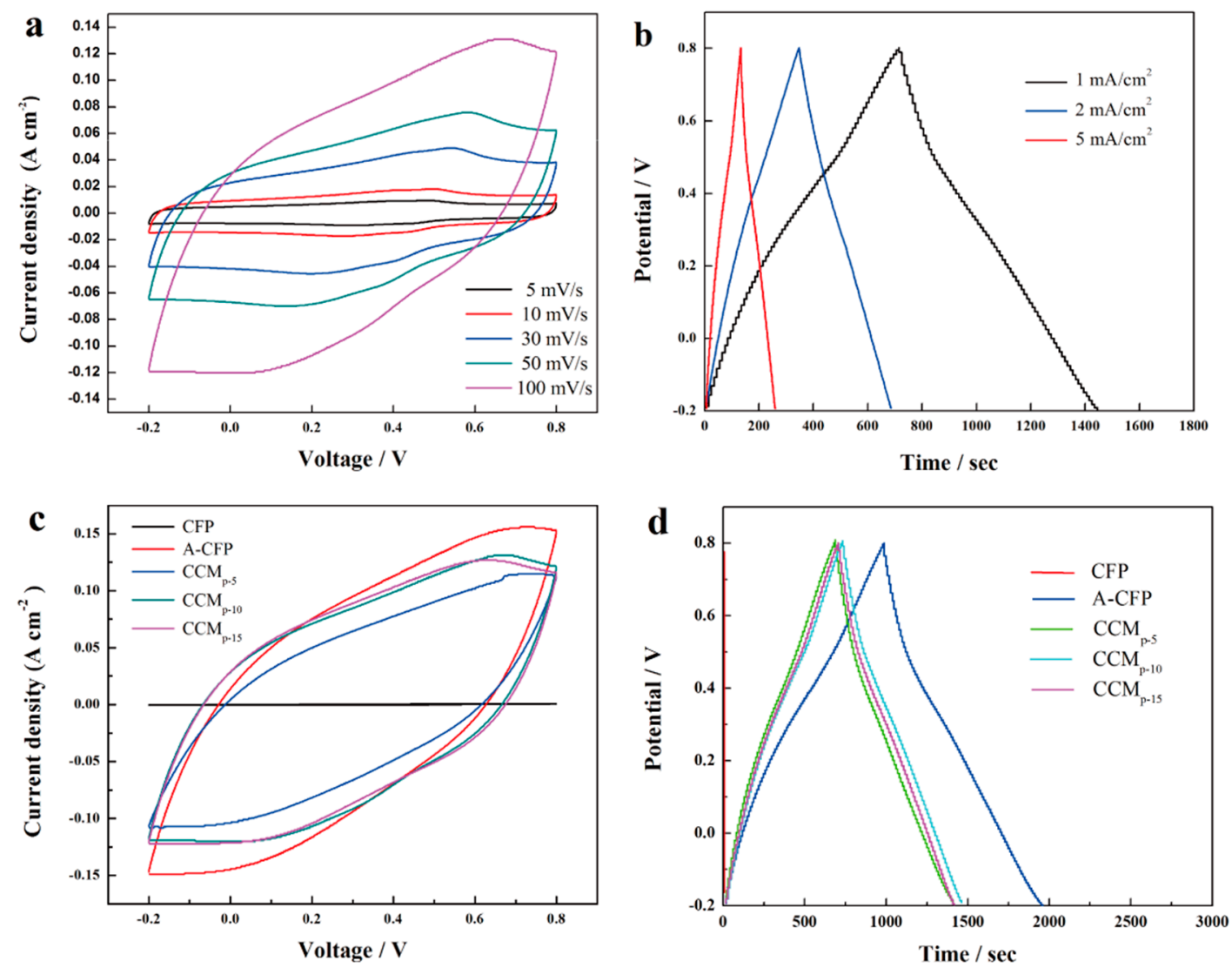

Figure 9. $\mathrm{CV}$ loops of $\mathrm{CCM}_{\mathrm{p}-10}(\mathbf{a})$; $\mathrm{GCD}$ tests of $\mathrm{CCM}_{\mathrm{p}-10}(\mathbf{b})$; comparison of $\mathrm{CV}$ loops of the raw CFP, A-CFP, $\mathrm{CCM}_{\mathrm{p}-5}, \mathrm{CCM}_{\mathrm{p}-10}$, and $\mathrm{CCM}_{\mathrm{p}-15}$ (c); and comparison of GCD tests of the raw CFP, A-CFP, $\mathrm{CCM}_{\mathrm{p}-5}, \mathrm{CCM}_{\mathrm{p}-10}$, and $\mathrm{CCM}_{\mathrm{p}-15}(\mathbf{d})$.

In order to investigate the effect of polymerization time on PANI in $\mathrm{CCM}_{\mathrm{p}-10}, \mathrm{CHI} 660 \mathrm{E}$ was also used to assess the electrochemical performance of the samples. Figure 10a showed the cyclic voltammogram curves of the $\mathrm{CCM}_{\mathrm{s}-6}$ electrode at different scan rates in $1 \mathrm{M} \mathrm{H}_{2} \mathrm{SO}_{4}$. Typical redox peaks of PANI could be clearly observed under low scan rates with oxidation peaks located at about $0.22 \mathrm{~V}$ and $0.52 \mathrm{~V}$, and a reduction peak at $0.41 \mathrm{~V}$ demonstrated the great capacitance performance of $\mathrm{CCM}_{\mathrm{s}-6}$. However, the redox peaks decreased with the increase of scan rate, and at a high scan rate of $100 \mathrm{mV} / \mathrm{s}$, the cathodic peaks and the anodic peaks disappeared totally, which may due to the lack of time for redox reactions. Further, the shape of the CV loops of $\mathrm{CCM}_{\mathrm{s}-6}$ expanded stably, which suggested the good reversibility and charge propagation of the electrodes. The capacitance of the $\mathrm{CCM}_{\mathrm{s}-6}$ is calculated to be $3000,2500,1983,1519$, and $860 \mathrm{mF} \cdot \mathrm{cm}^{-2}$ at 5, 10, 30, 50, and $100 \mathrm{mV} \cdot \mathrm{s}^{-1}$, respectively. To demonstrate the effect of polymerization time on the electrochemical performance of the electrodes, comparisons of $\mathrm{CV}$ curves at $5 \mathrm{mV} \cdot \mathrm{s}^{-1}$ of different samples were carried out. As shown in Figure 10c, $\mathrm{CCM}_{\mathrm{s}-2}, \mathrm{CCM}_{\mathrm{s}-4}, \mathrm{CCM}_{\mathrm{s}-6}, \mathrm{CCM}_{\mathrm{s}-8}, \mathrm{CCM}_{\mathrm{s}-24}$, and $\mathrm{C}_{\mathrm{p}-6}$ all possessed higher integral area than $\mathrm{CCM}_{\mathrm{p}-10}$, which indicates that the deposited PANI indeed enhanced the capacitance performance of $\mathrm{CCM}_{\mathrm{p}-10}$. However, PANI directly deposited on A-CFP $\left(\mathrm{C}_{\mathrm{p}-6}\right)$ show limited enhancement, which may due to that $6 \mathrm{~h}$ of polymerization could not fully utilize the A-CFP surface. The partial growth of PANI on the surface of A-CFP has been investigated in the SEM images before (Figure 3a). The specific 
capacitance of $\mathrm{CCM}_{\mathrm{s}-2}, \mathrm{CCM}_{\mathrm{s}-4}, \mathrm{CCM}_{\mathrm{s}-6}, \mathrm{CCM}_{\mathrm{s}-8}, \mathrm{CCM}_{\mathrm{s}-24}$, and $\mathrm{C}_{\mathrm{p}-6}$ was calculated to be 2810,2862 , $3082,3412,2803$, and $2008 \mathrm{mF} \cdot \mathrm{cm}^{-2}$. After then, galvanostatic charging/discharging measurements were further used to characterize the electrochemical performance of the samples. Figure 10b shows the GCD curves of $\mathrm{CCM}_{\mathrm{s}-6}$ at different current densities verified from 1 to $5 \mathrm{~mA} \cdot \mathrm{cm}^{-2}$. The specific area capacitance was calculated to be 1706,1560 , and $1430 \mathrm{mF} \cdot \mathrm{cm}^{-2}$ at corresponding current densities of 1,2 , and $5 \mathrm{~mA} \cdot \mathrm{cm}^{-2}$. The capacitance decreased by increasing the current densities, which were consistent with the CV measurement. Notably, this is a remarkable value when compared to the recently reported electrodes listed in Table 1. Comparison of GCD curves of $\mathrm{CCM}_{\mathrm{p}-10}, \mathrm{CCM}_{\mathrm{s}-2}$, $\mathrm{CCM}_{\mathrm{s}-4}, \mathrm{CCM}_{\mathrm{s}-6}, \mathrm{CCM}_{\mathrm{s}-8}, \mathrm{CCM}_{\mathrm{s}-24}$, and $\mathrm{C}_{\mathrm{p}-6}$ were shown in Figure $10 \mathrm{~d}$. Compared to $\mathrm{CCM}_{\mathrm{p}-10}$, all the discharge curves were not ideal straight lines, which demonstrated a faradic reaction process of PANI. The shape of $\mathrm{CCM}_{\mathrm{s}-6}$ was almost symmetric, which suggested the ideal capacitive nature of the electrode. Figure 10e,f illustrated the rate capability of the samples. The practical capacitance of the samples increased with the increasing polymerization time, but due to the acceleration decrease of capacitance at high scan rates and current densities for $\mathrm{CCM}_{\mathrm{s}-8}$, we chose $\mathrm{CCM}_{\mathrm{s}-6}$ as electrodes to fabricate symmetrical supercapacitors. The electrochemical performance of the samples was further evaluated by electrical impedance specteoscopy (EIS), and the Nyquist plots are shown in Figure 10g. In the EIS spectrum, the ohmic internal resistance (Rs) is equal to the value of intercept on the X-axis at a high frequency, while the diameter of the semicircle represents the charge transfer resistance (Rct) [38]. The Rs for $\mathrm{CCM}_{\mathrm{s}-6}$ was the lowest among the samples, and the value was about $1.1 \Omega$. Moreover, the low frequency line of all the plots showed a nearly vertical shape with a slope of about $60^{\circ}$, which suggested faster ion diffusion behavior. An obvious semicircle shape could be observed in $\mathrm{CCM}_{\mathrm{s}-4}$, indicating relatively higher interfacial resistance and decreased conductivity. This may be explained the fact that the synthesis of PANI could be accomplished in $4 \mathrm{~h}$ and would suffer from hydrolysis in the following reaction time [39]. Further, the extra synthesized PANI may block the diffusion channel of ions into the inner space of the electrodes.

For the practical application, the cycle stability of $\mathrm{CCM}_{\mathrm{s}-6}$ was tested by conducting continuous galvanostatic charging/discharging measurements at $50 \mathrm{~mA} \cdot \mathrm{cm}^{-2}$. The electrode retained approximately $76.5 \%$ of its initial capacitance $\left(850 \mathrm{mF} \cdot \mathrm{cm}^{-2}\right)$ after 5000 times cycle and even retained $70.6 \%$ of the capacitance after 10,000 times of cycling. This result confirmed the good stability of the carbon fiber paper-based electrode.

The practical electrochemical performance of the electrode was further evaluated by assessing the property of the assembled symmetric supercapacitors. Figure 11a showed the CV curves of the ASSC at different scan rates. Although the shape of the CV loops become narrower compared to single electrode, which may be caused by the imperfect contact between the two electrodes, the symmetric shape was still retained. For GCD curves of the ASSC (Figure 11b), all the curves show symmetric and straight lines, indicating the ideal capacitive nature of the sample, and a high area capacitance of $626 \mathrm{mF} \cdot \mathrm{cm}^{-2}$ was achieved at $0.5 \mathrm{~mA} \cdot \mathrm{cm}^{-2}$. The EIS spectrum of the ASSC showed the resistance of the supercapacitor was rather small, and the straight line at low frequency with a slop of about $60^{\circ}$ suggested the ideal capacitive nature (Figure 11c). Further, as shown in Figure 11d, the ASSC achieved a high power density of $250.3 \mu \mathrm{W} \mathrm{cm}{ }^{-2}$ with energy density of $87 \mu \mathrm{Wh} \cdot \mathrm{cm}^{-2}$ at $0.5 \mathrm{~mA} \cdot \mathrm{cm}^{-2}$.

Table 1. Comparison of the capacitance of different electrode materials.

\begin{tabular}{|c|c|c|c|}
\hline Electrode Materials & Electrolyte & Capacitance $\left(\mathrm{mF} \cdot \mathrm{cm}^{-2}\right)$ & Ref. \\
\hline CNT/PANI hydrogel film & $1 \mathrm{M} \mathrm{H}_{2} \mathrm{SO}_{4}$ & 680 & [40] \\
\hline Graphene/PANI aerogels & $\mathrm{H}_{2} \mathrm{SO}_{4} / \mathrm{PVA}$ & 679 & [41] \\
\hline Carbon fiber paper & $6 \mathrm{M} \mathrm{KOH}$ & 750 & [42] \\
\hline Graphene/polypyrrole & $\mathrm{H}_{2} \mathrm{SO}_{4} / \mathrm{PVA}$ & 477 & [43] \\
\hline CNT/polypyrrole & $\mathrm{H}_{3} \mathrm{PO}_{4} / \mathrm{PVA}$ & 27.8 & [44] \\
\hline $\begin{array}{c}\text { Organometal halide perovskite solar } \\
\text { cells /CNT/PANI }\end{array}$ & PVA & 422 & [45] \\
\hline
\end{tabular}



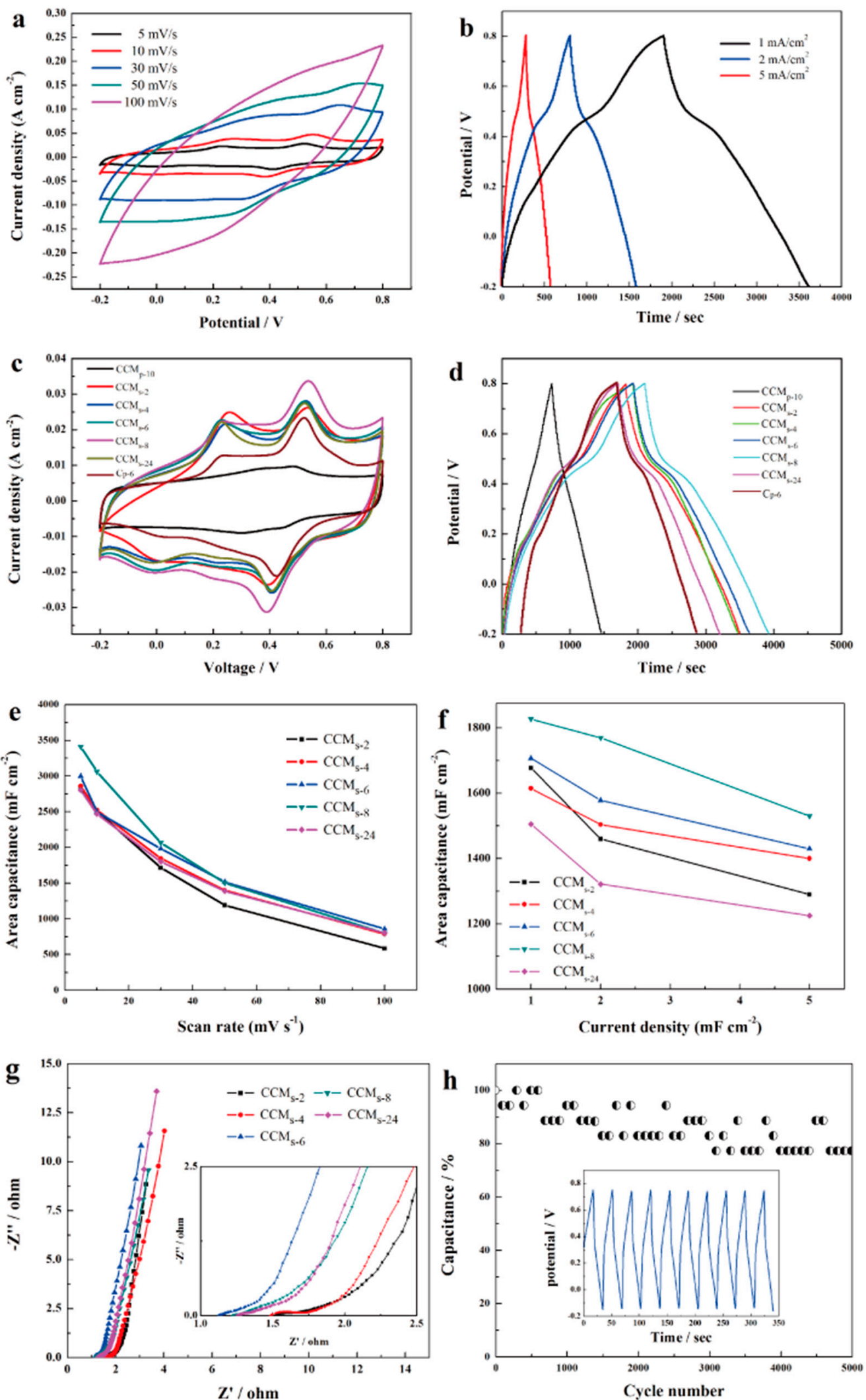

Figure 10. $\mathrm{CV}$ curve of $\mathrm{CCM}_{\mathrm{s}-6}$ at different scan rates (a); GCD curves of $\mathrm{CCM}_{\mathrm{s}-6}$ at different current densities (b); comparison of CV loops of the samples (c); comparison of GCD curves of the samples (d); rate capacity of $\mathrm{CCM}_{\mathrm{s}-2}, \mathrm{CCM}_{\mathrm{s}-4}, \mathrm{CCM}_{\mathrm{s}-6}, \mathrm{CCM}_{\mathrm{s}-8}$ and $\mathrm{CCM}_{\mathrm{s}-24}(\mathbf{e}, \mathbf{f})$; EIS spectrum of $\mathrm{CCM}_{\mathrm{s}-2}$, $\mathrm{CCM}_{\mathrm{s}-4}, \mathrm{CCM}_{\mathrm{s}-6}, \mathrm{CCM}_{\mathrm{s}-8}$ and $\mathrm{CCM}_{\mathrm{s}-24}(\mathrm{~g})$; and the capacitance retention of $\mathrm{CCM}_{\mathrm{s}-6}$ after 5000 times of cycling (h). 

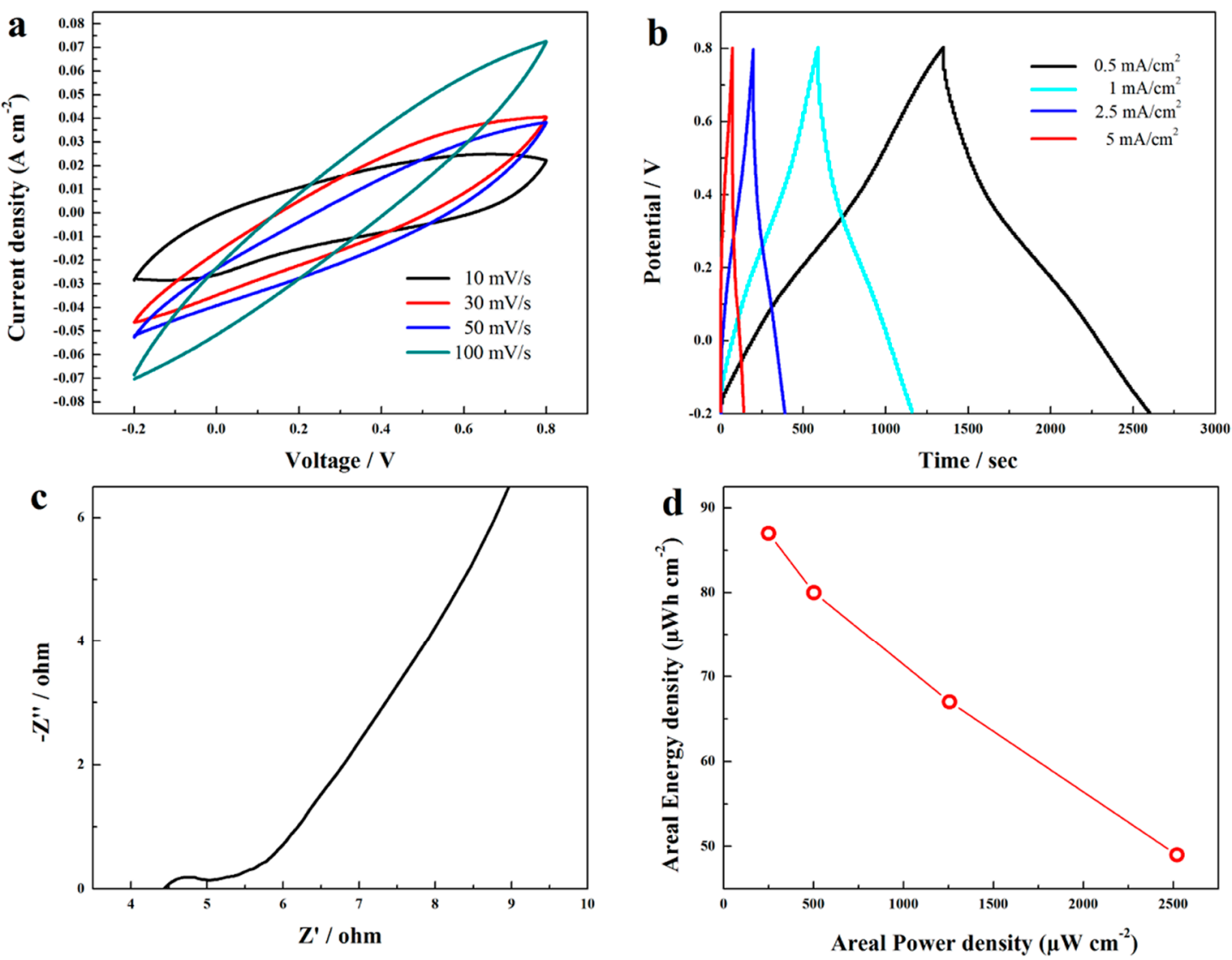

Figure 11. CV loops of the assembled symmetric supercapacitor at different scan rates (a); GCD curves of the ASSC at different current densities (b); EIS of the ASSC (c); and comparison of power density and energy density of the ASSC (d).

\section{Conclusions}

In summary, we have successfully fabricated A-CFP/CNFs-CNTs/PANI hybrid paper electrode for supercapacitors using a simple, low-cost, and effective method. The existence of the CNFs/CNTs mixture provided more active sites for the polymerization of PANI and thus achieved enhanced capacitance of $1706 \mathrm{~mA} \cdot \mathrm{cm}^{-2}$ and long-term cycle stability (it retained $70.6 \%$ of its initial capacitance). Further, the assembled symmetric supercapacitors delivered high area-capacitances of $1251 \mathrm{mF} \cdot \mathrm{cm}^{-2}$, $87 \mu \mathrm{Wh} \cdot \mathrm{cm}^{-2}$ of area energy density and $250.3 \mu \mathrm{W} \cdot \mathrm{cm}^{-2}$ of power density. It is believed that the as-prepared products could be promising electrodes for supercapacitors.

Author Contributions: Conceptualization, S.T. and Z.X.; Methodology, S.T.; Software, J.L.; Validation, J.S.; Formal Analysis, S.T.; Investigation, P.C.; Resources, L.Z.; Data Curation, S.T.; Writing-Original Draft Preparation, S.T.; Writing-Review \& Editing, S.T.; Visualization, S.T.; Supervision, S.T.; Project Administration, Z.X.; Funding Acquisition, Z.X.

Funding: This work was funded by the National Key Research and Development Program of China grant number 2017YFD0600204, the National Natural Science Foundation of China, grant No. 31770607, the Natural Science Foundation of Jiangsu Province of China, grant No. BK20171450, and a project funded by the Priority Academic Program Development of Jiangsu Higher Education Institutions (PAPD). The authors acknowledge the Advanced Analysis \& Testing Center of Nanjing Forestry University.

Acknowledgments: This work was supported by the National Key Research and Development Program of China (2017YFD0600204), the National Natural Science Foundation of China (grant No. 31770607), the Natural Science Foundation of Jiangsu Province of China (grant No. BK20171450), and a project funded by the Priority Academic Program Development of Jiangsu Higher Education Institutions (PAPD). The authors acknowledge the Advanced Analysis \& Testing Center of Nanjing Forestry University.

Conflicts of Interest: The authors declare that they have no conflict of interest. 


\section{References}

1. Ma, C.; Li, Y.; Shi, J.; Song, Y.; Liu, L. High-performance supercapacitor electrodes based on porous flexible carbon nanofiber paper treated by surface chemical etching. Chem. Eng. J. 2014, 249, 216-225. [CrossRef]

2. Srimuk, P.; Luanwuthi, S.; Krittayavathananon, A.; Sawangphruk, M. Solid-type supercapacitor of reduced graphene oxide-metal organic framework composite coated on carbon fiber paper. Electrochim. Acta 2015, 157, 69-77. [CrossRef]

3. Xiao, J.; Wan, L.; Yang, S.; Xiao, F.; Wang, S. Design Hierarchical Electrodes with Highly Conductive $\mathrm{NiCo}_{2} \mathrm{~S}_{4}$ Nanotube Arrays Grown on Carbon Fiber Paper for High-Performance Pseudocapacitors. Nano Lett. 2014, 14, 831-838. [CrossRef] [PubMed]

4. Huang, L.; Chen, D.; Ding, Y.; Feng, S.; Wang, Z.L.; Liu, M. Nickel-Cobalt Hydroxide Nanosheets Coated on $\mathrm{NiCo}_{2} \mathrm{O}_{4}$ Nanowires Grown on Carbon Fiber Paper for High-Performance Pseudocapacitors. Nano Lett. 2013, 13, 3135-3139. [CrossRef] [PubMed]

5. Rakhi, R.B.; Alshareef, H.N. Enhancement of the energy storage properties of supercapacitors using graphene nanosheets dispersed with metal oxide-loaded carbon nanotubes. J. Power Sources 2011, 196, 8858-8865. [CrossRef]

6. Vangari, M.; Pryor, T.; Jiang, L. Supercapacitors: Review of Materials and Fabrication Methods. J. Energy Eng. 2013, 139, 72-79. [CrossRef]

7. Muniraj, V.K.A.; Kamaja, C.K.; Shelke, M.V. $\mathrm{RuO}_{2} \cdot \mathrm{nH}_{2} \mathrm{O}$ Nanoparticles Anchored on Carbon Nano-onions: An Efficient Electrode for Solid State Flexible Electrochemical Supercapacitor. ACS Sustain. Chem. Eng. 2016, 4, 2528-2534. [CrossRef]

8. Sumboja, A.; Foo, C.Y.; Wang, X.; Lee, P.S. Large Areal Mass, Flexible and Free-Standing Reduced Graphene Oxide/Manganese Dioxide Paper for Asymmetric Supercapacitor Device. Adv. Mater. 2013, 25, 2809-2815. [CrossRef] [PubMed]

9. Rakhi, R.B.; Chen, W.; Hedhili, M.N.; Cha, D.; Alshareef, H.N. Enhanced Rate Performance of Mesoporous $\mathrm{Co}_{3} \mathrm{O}_{4}$ Nanosheet Supercapacitor Electrodes by Hydrous $\mathrm{RuO}_{2}$ Nanoparticle Decoration. ACS Appl. Mater. Interfaces 2014, 6, 4196-4206. [CrossRef] [PubMed]

10. Yu, G.; Hu, L.; Liu, N.; Wang, H.; Vosgueritchian, M.; Yang, Y.; Cui, Y.; Bao, Z. Enhancing the Supercapacitor Performance of Graphene/ $\mathrm{MnO}_{2}$ Nanostructured Electrodes by Conductive Wrapping. Nano Lett. 2011, 11, 4438-4442. [CrossRef] [PubMed]

11. Peng, H.; Ma, G.; Ying, W.; Wang, A.; Huang, H.; Lei, Z. In situ synthesis of polyaniline/sodium carboxymethyl cellulose nanorods for high-performance redox supercapacitors. J. Power Sources 2012, 211, 40-45. [CrossRef]

12. Kim, J.-W.; Siochi, E.J.; Carpena-Núñez, J.; Wise, K.E.; Connell, J.W.; Lin, Y.; Wincheski, R.A. Polyaniline/ Carbon Nanotube Sheet Nanocomposites: Fabrication and Characterization. ACS Appl. Mater. Interfaces 2013, 5, 8597-8606. [CrossRef] [PubMed]

13. Wang, H.; Liu, J.; Chen, Z.; Chen, S.; Sum, T.C.; Lin, J.; Shen, Z.X. Synergistic capacitive behavior between polyaniline and carbon black. Electrochim. Acta 2017, 230, 236-244. [CrossRef]

14. Niu, Z.; Luan, P.; Shao, Q.; Dong, H.; Li, J.; Chen, J.; Zhao, D.; Cai, L.; Zhou, W.; Chen, X.; et al. A "skeleton/skin" strategy for preparing ultrathin free-standing single-walled carbon nanotube/polyaniline films for high performance supercapacitor electrodes. Energy Environ. Sci. 2012, 5, 8726-8733. [CrossRef]

15. Zhang, J.; Kong, L.-B.; Wang, B.; Luo, Y.-C.; Kang, L. In-situ electrochemical polymerization of multi-walled carbon nanotube/polyaniline composite films for electrochemical supercapacitors. Synth. Met. 2009, 159, 260-266. [CrossRef]

16. Wang, K.; Meng, Q.; Zhang, Y.; Wei, Z.; Miao, M. High-Performance Two-Ply Yarn Supercapacitors Based on Carbon Nanotubes and Polyaniline Nanowire Arrays. Adv. Mater. 2013, 25, 1494-1498. [CrossRef] [PubMed]

17. Zhu, W.; Zhang, Y.; Zhou, X.; Xu, J.; Liu, Z.; Yuan, N.; Ding, J. Miniaturized Stretchable and High-Rate Linear Supercapacitors. Nanoscale Res. Lett. 2017, 12. [CrossRef] [PubMed]

18. Show, Y.; Imaizumi, K. Electric double layer capacitor with low series resistance fabricated by carbon nanotube addition. Diam. Relat. Mater. 2007, 16, 1154-1158. [CrossRef]

19. Geng, Y.; Liu, M.Y.; Li, J.; Shi, X.M.; Kim, J.K. Effects of surfactant treatment on mechanical and electrical properties of CNT/epoxy nanocomposites. Compos. Part Appl. Sci. Manuf. 2008, 39, 1876-1883. [CrossRef] 
20. Shi, X.; Hu, Y.; Fu, F.; Zhou, J.; Wang, Y.; Chen, L.; Zhang, H.; Li, J.; Wang, X.; Zhang, L. Construction of PANI-cellulose composite fibers with good antistatic properties. J. Mater. Chem. A 2014, 2, 7669-7673. [CrossRef]

21. Miao, C.; Hamad, W.Y. Cellulose reinforced polymer composites and nanocomposites: A critical review. Cellulose 2013, 20, 2221-2262. [CrossRef]

22. Kim, Y.; McCoy, L.T.; Lee, E.; Lee, H.; Saremi, R.; Feit, C.; Hardin, I.R.; Sharma, S.; Mani, S.; Minko, S. Environmentally sound textile dyeing technology with nanofibrillated cellulose. Green Chem. 2017, 19, 4031-4035. [CrossRef]

23. Czaja, W.K.; Young, D.J.; Kawecki, M.; Brown, R.M. The Future Prospects of Microbial Cellulose in Biomedical Applications. Biomacromolecules 2007, 8, 1-12. [CrossRef] [PubMed]

24. Gui, Z.; Zhu, H.; Gillette, E.; Han, X.; Rubloff, G.W.; Hu, L.; Lee, S.B. Natural Cellulose Fiber as Substrate for Supercapacitor. ACS Nano 2013, 7, 6037-6046. [CrossRef] [PubMed]

25. Siró, I.; Plackett, D. Microfibrillated cellulose and new nanocomposite materials: A review. Cellulose 2010, 17, 459-494. [CrossRef]

26. Suktha, P.; Chiochan, P.; Iamprasertkun, P.; Wutthiprom, J.; Phattharasupakun, N.; Suksomboon, M.; Kaewsongpol, T.; Sirisinudomkit, P.; Pettong, T.; Sawangphruk, M. High-Performance Supercapacitor of Functionalized Carbon Fiber Paper with High Surface Ionic and Bulk Electronic Conductivity: Effect of Organic Functional Groups. Electrochim. Acta 2015, 176, 504-513. [CrossRef]

27. Chen, W.; Yu, H.; Liu, Y. Preparation of millimeter-long cellulose I nanofibers with diameters of 30-80 nm from bamboo fibers. Carbohydr. Polym. 2011, 86, 453-461. [CrossRef]

28. Yan, X.; Tai, Z.; Chen, J.; Xue, Q. Fabrication of carbon nanofiber-polyaniline composite flexible paper for supercapacitor. Nanoscale 2011, 3, 212-216. [CrossRef] [PubMed]

29. Liu, S.; Li, D. Synthesis of chitin nanofibers, MWCNTs and $\mathrm{MnO}_{2}$ nanoflakes 3D porous network flexible gel-film for high supercapacitive performance electrodes. Appl. Surf. Sci. 2017, 398, 33-42. [CrossRef]

30. Yang, C.; Chen, C.; Pan, Y.; Li, S.; Wang, F.; Li, J.; Li, N.; Li, X.; Zhang, Y.; Li, D. Flexible highly specific capacitance aerogel electrodes based on cellulose nanofibers, carbon nanotubes and polyaniline. Electrochim. Acta 2015, 182, 264-271. [CrossRef]

31. Wang, Z.; Han, Y.; Zeng, Y.; Qie, Y.; Wang, Y.; Zheng, D.; Lu, X.; Tong, Y. Activated carbon fiber paper with exceptional capacitive performance as a robust electrode for supercapacitors. J. Mater. Chem. A 2016, 4, 5828-5833. [CrossRef]

32. Zhang, F.; Pang, Z.; Dong, C.; Liu, Z. Preparing cationic cotton linter cellulose with high substitution degree by ultrasonic treatment. Carbohydr. Polym. 2015, 132, 214-220. [CrossRef] [PubMed]

33. Zhu, Y.; Cheng, S.; Zhou, W.; Jia, J.; Yang, L.; Yao, M.; Wang, M.; Wu, P.; Luo, H.; Liu, M. Porous Functionalized Self-Standing Carbon Fiber Paper Electrodes for High-Performance Capacitive Energy Storage. ACS Appl. Mater. Interfaces 2017, 9, 13173-13180. [CrossRef] [PubMed]

34. Gardner, S.D.; Singamsetty, C.S.K.; Booth, G.L.; He, G.-R.; Pittman, C.U., Jr. Surface characterization of carbon fibers using angle-resolved XPS and ISS. Carbon 1995, 33, 587-595. [CrossRef]

35. Golczak, S.; Kanciurzewska, A.; Fahlman, M.; Langer, K.; Langer, J. Comparative XPS surface study of polyaniline thin films. Solid State Ion. 2008, 179, 2234-2239. [CrossRef]

36. Kaewsongpol, T.; Sawangphruk, M.; Chiochan, P.; Suksomboon, M.; Suktha, P.; Srimuk, P.; Krittayavathananon, A.; Luanwuthi, S.; Iamprasertkun, P.; Wutthiprom, J.; et al. High-performance supercapacitor of electrodeposited porous 3D polyaniline nanorods on functionalized carbon fiber paper: Effects of hydrophobic and hydrophilic surfaces of conductive carbon paper substrates. Mater. Today Commun. 2015, 4, 176-185. [CrossRef]

37. Zheng, Q.; Cai, Z.; Ma, Z.; Gong, S. Cellulose Nanofibril/Reduced Graphene Oxide/Carbon Nanotube Hybrid Aerogels for Highly Flexible and All-Solid-State Supercapacitors. ACS Appl. Mater. Interfaces 2015, 7, 3263-3271. [CrossRef] [PubMed]

38. Lu, X.; Zeng, Y.; Yu, M.; Zhai, T.; Liang, C.; Xie, S.; Balogun, M.-S.; Tong, Y. Oxygen-Deficient Hematite Nanorods as High-Performance and Novel Negative Electrodes for Flexible Asymmetric Supercapacitors. Adv. Mater. 2014, 26, 3148-3155. [CrossRef] [PubMed]

39. Gospodinova, N.; Mokreva, P.; Terlemezyan, L. Influence of hydrolysis on the chemical polymerization of aniline. Polymer 1994, 35, 3102-3106. [CrossRef] 
40. Zeng, S.; Chen, H.; Cai, F.; Kang, Y.; Chen, M.; Li, Q. Electrochemical fabrication of carbon nanotube/ polyaniline hydrogel film for all-solid-state flexible supercapacitor with high areal capacitance. J. Mater. Chem. A 2015, 3, 23864-23870. [CrossRef]

41. Qu, Y.; Lu, C.; Su, Y.; Cui, D.; He, Y.; Zhang, C.; Cai, M.; Zhang, F.; Feng, X.; Zhuang, X. Hierarchicalgraphene-coupled polyaniline aerogels for electrochemical energy storage. Carbon 2018, 127, 77-84. [CrossRef]

42. Zhang, H.; Qiu, W.; Zhang, Y.; Han, Y.; Yu, M.; Wang, Z.; Lu, X.; Tong, Y. Surface engineering of carbon fiber paper for efficient capacitive energy storage. J. Mater. Chem. A 2016, 4, 18639-18645. [CrossRef]

43. Yang, C.; Zhang, L.; Hu, N.; Yang, Z.; Wei, H.; Wang, Y.; Zhang, Y. High-performance flexible all-solid-state supercapacitors based on densely-packed graphene/polypyrrole nanoparticle papers. Appl. Surf. Sci. 2016, 387, 666-673. [CrossRef]

44. Zhou, Y.; Hu, X.; Shang, Y.; Hua, C.; Song, P.; Li, X.; Zhang, Y.; Cao, A. Highly flexible all-solid-state supercapacitors based on carbon nanotube/polypyrrole composite films and fibers. RSC Adv. 2016, 6, 62062-62070. [CrossRef]

45. Liu, R.; Liu, C.; Fan, S. A photocapacitor based on organometal halide perovskite and PANI/CNT composites integrated using a CNT bridge. J. Mater. Chem. A 2017, 5, 23078-23084. [CrossRef]

(C) 2018 by the authors. Licensee MDPI, Basel, Switzerland. This article is an open access article distributed under the terms and conditions of the Creative Commons Attribution (CC BY) license (http:/ / creativecommons.org/licenses/by/4.0/). 